\title{
Testing remote sensing on artificial observations: impact of drizzle and 3-D cloud structure on effective radius retrievals
}

\author{
T. Zinner ${ }^{1, *}$, G. Wind ${ }^{2}$, S. Platnick ${ }^{2}$, and A. S. Ackerman ${ }^{3}$ \\ ${ }^{1}$ Deutsches Zentrum für Luft- und Raumfahrt (DLR), Oberpfaffenhofen, Germany \\ ${ }^{2}$ NASA Goddard Space Flight Center, Greenbelt, USA \\ ${ }^{3}$ NASA Goddard Institute for Space Studies, New York, USA \\ *now at: Ludwig-Maximilians-Universität, München, Germany
}

Received: 9 December 2009 - Published in Atmos. Chem. Phys. Discuss.: 18 January 2010

Revised: 16 September 2010 - Accepted: 1 October 2010 - Published: 8 October 2010

\begin{abstract}
Remote sensing of cloud effective particle size with passive sensors like the Moderate Resolution Imaging Spectroradiometer (MODIS) is an important tool for cloud microphysical studies. As a measure of the radiatively relevant droplet size, effective radius can be retrieved with different combinations of visible through shortwave and midwave infrared channels. In practice, retrieved effective radii from these combinations can be quite different. This difference is perhaps indicative of different penetration depths and path lengths for the spectral reflectances used. In addition, operational liquid water cloud retrievals are based on the assumption of a relatively narrow distribution of droplet sizes; the role of larger precipitation particles in these distributions is neglected. Therefore, possible explanations for the discrepancy in some MODIS spectral size retrievals could include 3 -D radiative transport effects, including sub-pixel cloud inhomogeneity, and/or the impact of drizzle formation.

For three cloud cases the possible factors of influence are isolated and investigated in detail by the use of simulated cloud scenes and synthetic satellite data: marine boundary layer cloud scenes from large eddy simulations (LES) with detailed microphysics are combined with Monte Carlo radiative transfer calculations that explicitly account for the detailed droplet size distributions as well as 3-D radiative transfer to simulate MODIS observations. The operational MODIS optical thickness and effective radius retrieval algorithm is applied to these and the results are compared to the given LES microphysics.

We investigate two types of marine cloud situations each with and without drizzle from LES simulations: (1) a typical
\end{abstract}

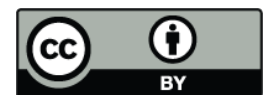

Correspondence to: $\mathrm{T}$. Zinner (tobias.zinner@1mu.de) daytime stratocumulus deck at two times in the diurnal cycle and (2) one scene with scattered cumulus. Only small impact of drizzle formation on the retrieved domain average and on the differences between the three effective radius retrievals is noticed for both cloud scene types for different reasons. For our, presumably typical, overcast stratocumulus scenes with an optical thickness of 8 to 9 and rain rates at cloud bottom up to $0.05 \mathrm{~mm} / \mathrm{h}$ clear drizzle impact on the retrievals can be excluded. The cumulus scene does not show much drizzle sensitivity either despite extended drizzle areas being directly visible from above (locally $>1 \mathrm{~mm} / \mathrm{h}$ ), which is mainly due to technical characteristics of the standard retrieval approach. 3-D effects, on the other hand, produce large discrepancies between the 1.6 and $2.1 \mu \mathrm{m}$ channel observations compared to $3.7 \mu \mathrm{m}$ retrievals in the latter case. A general sensitivity of MODIS particle size data to drizzle formation is not corroborated by our case studies.

\section{Introduction}

Standard passive cloud optical retrievals are based on simplifying assumptions: (1) clouds are assumed to be planeparallel homogeneous within each pixel, (2) pixels are radiatively independent, and (3) clouds consist of cloud droplets only, i.e., any drizzle or precipitation modes are ignored. The impact of real cloud situations not fulfilling these assumptions has been investigated in several studies. Cahalan et al. (1994) describe the plane-parallel bias as well as the independent pixel uncertainty caused by the first two assumptions respectively. Several studies investigated the impacts of both assumptions on standard cloud property retrievals and tried to quantify them (e.g. Loeb et al., 1998; Varnai and Marshak, 2001; Zinner and Mayer, 2006; Varnai and Marshak, 2007).

Published by Copernicus Publications on behalf of the European Geosciences Union. 
Most were concerned with optical thickness retrievals. Impacts on effective size retrievals have also been investigated (e.g. Platnick, 2000; Chang and Li, 2003; Marshak et al., 2006; Vant-Hull et al., 2007). The third assumption has received much less attention. Minnis et al. (2004) point to the possibility of underestimating effective droplet radius in pristine marine boundary layer clouds containing drizzle, because standard retrievals assume a monomodal, narrow size distribution for cloud droplets. Chang and $\mathrm{Li}$ (2003) estimate the vertical profile of effective radius for water clouds by using the different three MODIS retrievals and the fact that they offer different penetration depths into the cloud. They speculate on the possibility of detecting precipitation formation whenever the usually positive gradient of effective radius (increasing with height) turns neutral or even negative. Along this line Chen et al. (2008) investigated the detectability of drizzle in the MODIS retrievals. For strong drizzle formation (rain rates $>0.1 \mathrm{~mm} / \mathrm{h}$ at cloud base), the impact on the spectral effective radius retrievals implied decreasing effective radius retrievals with height, instead of the (for boundary layer clouds) usually expected increase with height.

The typical size distribution of cloud droplets used in the radiative transfer simulations that create the forward libraries of plane-parallel cloud properties and reflectances has a relatively narrow fixed width distribution with effective radius as the only free variable. The width of the distribution (effective variance) is usually regarded to be of minor importance. Hansen and Travis (1974) show that the three key single scattering characteristics: the scattering efficiency, the single scattering albedo, and the asymmetry parameter of a size distribution are approaching similar values depending only on its effective radius and hardly on its width in the limit of large particles (large compared to wavelength, i.e., $2 \pi r / \lambda \gg 1$ ). This result is usually adopted for the treatment of radiative transfer in clouds, e.g., in standard retrieval techniques for cloud properties (e.g., Nakajima and King, 1990). For this purpose, Gamma function or log-normal size distributions defined by a range of effective radii $\left(r_{\text {eff }}\right)$, and by a dimensionless effective variance, $v_{\text {eff }}$, from 0.05 to 0.13 are often used. For example, in the MODIS cloud retrieval MOD06 (Platnick et al., 2003), $r_{\text {eff }}=4-30 \mu \mathrm{m}$ and $v_{\text {eff }}=0.1$. From such analytic monomodal narrow droplet size distributions (DSD), optical properties representing non-precipitating water clouds can be derived via Mie calculations.

Once collisional droplet growth becomes active, the size distributions can develop a significant tail. Usually the presence of a few large precipitation size drops is regarded as negligible in radiative transport simulation, because they do not contribute much to the overall cross section that defines the extinction. For rain drops at sizes of much more than $1 \mathrm{~mm}$ this is probably correct, but precipitation often develops through a pronounced drizzle stage - especially in a marine boundary layer environment with potentially low cloud condensation nuclei numbers and weak vertical development. Drizzle drops in the size range just beyond typical

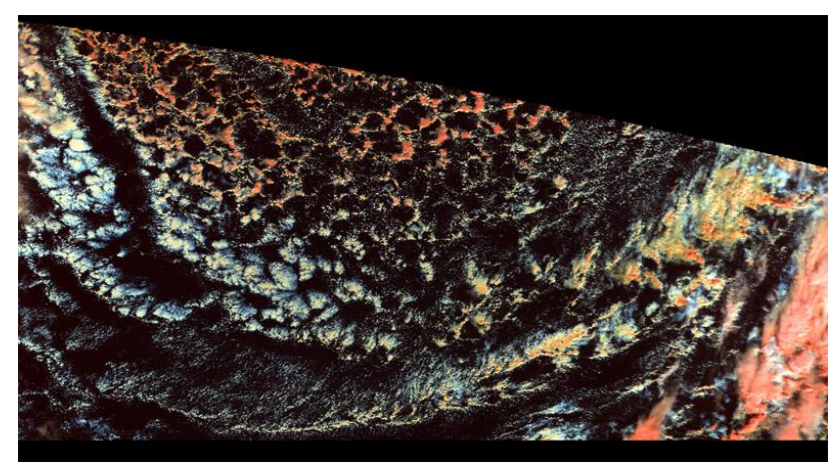

Fig. 1. False color composite $(\mathrm{R}, \mathrm{G}, \mathrm{B}=0.65,1.6,2.1 \mu \mathrm{m})$ of a stratocumulus scene over the northern subtropical Atlantic, 21 November 2004, 14:30 UTC, $1 \mathrm{~km}$ MODIS Terra data.

cloud droplet sizes of 5-15 $\mu \mathrm{m}$ are much more numerous than larger rain drops. This is why some studies show that drizzle formation should have an impact on single scattering properties (Minnis et al., 2004), that it is detectable in passive remote sensing observations (Chang and $\mathrm{Li}, 2003$; Chen et al., 2008), or that precipitating clouds tend to show larger effective particle size in satellite data (Leon et al., 2008; Lebsock, et al., 2008).

At the same time, MODIS observations of low marine cloud horizontal morphology, which is often associated with drizzle processes, can show interesting microphysical features. Figure 1 shows a false color composite image of open and closed marine stratocumulus cells in the subtropical Atlantic $(\sim 28 \mathrm{~N}, 60 \mathrm{~W})$. Obvious is the difference in coloration of the open cells, usually linked to drizzle formation (Stevens et al., 2005; Wood et al., 2008), seen in the upper left/middle portion of the image, compared to the closed cells just to the south (left central part of the image). In this false color image, red hues mark cloud regions with reduced shortwave infrared (SWIR) reflectances compared to the visible and nearinfrared parts of the spectrum. This smaller ratio can result from large, strongly absorbing ice particles (cf. the cirrus clouds in the lower right) or from large droplets. The evaluation of the MODIS effective radius retrievals for the open cell area in the upper left of Figure 1 reveals that the $r_{\text {eff }}$ retrievals from the $0.86 / 3.7 \mu \mathrm{m}$ channel combination shows smaller droplets than the retrieval from $0.86 / 2.1 \mu \mathrm{m}$ combination (Fig. 2).

This would be consistent with the picture that for the channel where radiation is less absorbed by liquid water, $2.1 \mu \mathrm{m}$, the increasing influence of drizzle formation deeper down in the cloud is detectable while the $3.7 \mu \mathrm{m}$ signal, where liquid water is strongly absorbing, is only affected by the particles from a shallower layer at the top of the clouds where drizzle modes are not significant.

Other candidate sources for this type of difference are shadow effects or cloud masking deficiencies affecting the MODIS retrieval (Ackerman et al., 1998). Cloud top height 


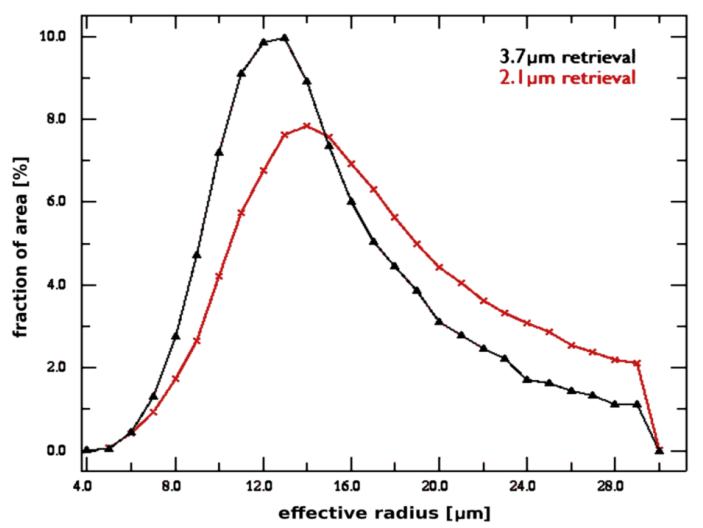

Fig. 2. Histogram of two MOD06 effective radius retrievals for the area of open cells in the upper left part of Fig. 1.

variations are large in this cloud type and region causing sharp shadows; cloud masking is not easy in this type of cloud with strong small scale contrasts of illuminated, shadowed, and cloud free areas. Both effects have the potential of mimicking large effective radius retrievals through small reflectivities in near infra-red channels (Marshak et al., 2006). However, in Fig. 1, shadowing would be expected to preferentially cause a high $r_{\text {eff }}$ bias when looking toward the sun (right side of image for this MODIS Terra case), which is not evident. 3-D effects would be expected to be stronger for weaker absorbing channels $(1.6$ or $2.1 \mu \mathrm{m})$ relative to $3.7 \mu \mathrm{m}$, as photon path lengths are the longer the smaller liquid water absorption is along the way. This however would give the opposite difference between the retrievals from that seen in Fig. 2.

There is no direct, unambiguous way to separate the various effects and therefore no simple way to validate any of the conclusions one might reach by analyzing the satellite observations alone. The large majority of investigations in the field are carried out on a theoretical level, e.g., generalized or simplified cloud structures used for forward radiative transfer simulations with little concern for specific realism of cloud structures, cloud microphysics, or retrieval algorithms. Alternatively, investigations are based on observational evidence alone, mostly satellite data without full knowledge of the underlying "truth", or available ground truth data, with very limited spatial coverage. Another approach is to use of synthetic satellite data based on realistic cloud simulations. Retrievals can be applied to these synthetic observations and subsequently retrieved properties can be compared to the given cloud properties. This approach has the further advantage that radiative transport (1-D or 3-D) as well as cloud condition (e.g., with or without drizzle, diurnal evolution, etc.) can be modified in a targeted manner to test the sensitivity of retrievals to the modified characteristic. The retrieval results can be analyzed within a fully controlled testing environment.
The cloud microphysical data sets for our tests are simulated with a Large Eddy Simulation (LES) cloud resolving model with size-resolved microphysics (Sect. 2.1). The optical properties associated to these marine boundary layer realizations are pre-processed before they serve as input to radiative transfer (Sects. 2.2 and 2.3). Section 4 presents the application of the MODIS-like cloud property retrieval (introduced in Sect. 3.2) for the derivation of effective radius from the simulation of five spectral channels (Sect. 3.1). Section 5 discusses the findings of the sensitivity studies.

\section{Cloud model}

This section presents the overall setup of three 3-D data sets of realistic spatial distributions of microphysical and optical properties presumably typical for drizzling boundary layer clouds. The data will form the basis of the later simulation of effective radius remote sensing. Originally, the cloud data for drizzling cloud scenes is provided by a LES cloud model with size-resolved microphysics (Sect. 2.1). In order to reduce the complexity of the full 3-D size distributions to serve as input to radiative transfer simulations and in order to facilitate the isolation of the drizzle impact, we separate the precipitation part of the simulated droplet spectra from the rest of the cloud structure (Sect. 2.2). Section 2.3 analyses the range of optical properties related to the given LES microphysical properties and compares them to the optical properties usually assumed within standard retrievals (alongside the separation of drizzle and cloud part of the LES data as presented in Sect. 2.2 is validated).

\subsection{LES cloud microphysics}

For the cloud model we use a 3-D large-eddy simulation code that resolves the size distributions of aerosol particles and liquid water drops (Ackerman et al., 2003). We analyze the results from two simulations: (1) an overcast stratocumulus case based on an idealization of conditions observed during the FIRE-I field project (a case described by Ackerman et al., 2004), and (2) a trade cumulus case based on a idealization of conditions observed during the RICO campaign (described in van Zanten et al., 2010). Table 1 gives an overview of the model setup for the simulations used in the following. Figure 3 shows some features of the stratocumulus deck at two times in the simulation (Sc 2 p.m. and $S c 6$ p.m.).

For the stratocumulus simulations, the model uses 25 size bins with droplet radius mid-points up to $256 \mu \mathrm{m}$. The grid mesh is $64 \times 64 \times 64$, with uniform 52.5 -m horizontal grid spacing and a stretched vertical grid that has minimum spacing of $\sim 5 \mathrm{~m}$ at the surface and at the initial cloud-top height. A total particle concentration (initially all particles are unactivated condensation nuclei) of $40 \mathrm{~cm}^{-3}$ is used; the domain-averaged droplet concentration (weighted by cloud water mixing ratio) is about $30 \mathrm{~cm}^{-3}$, thus these simulations 

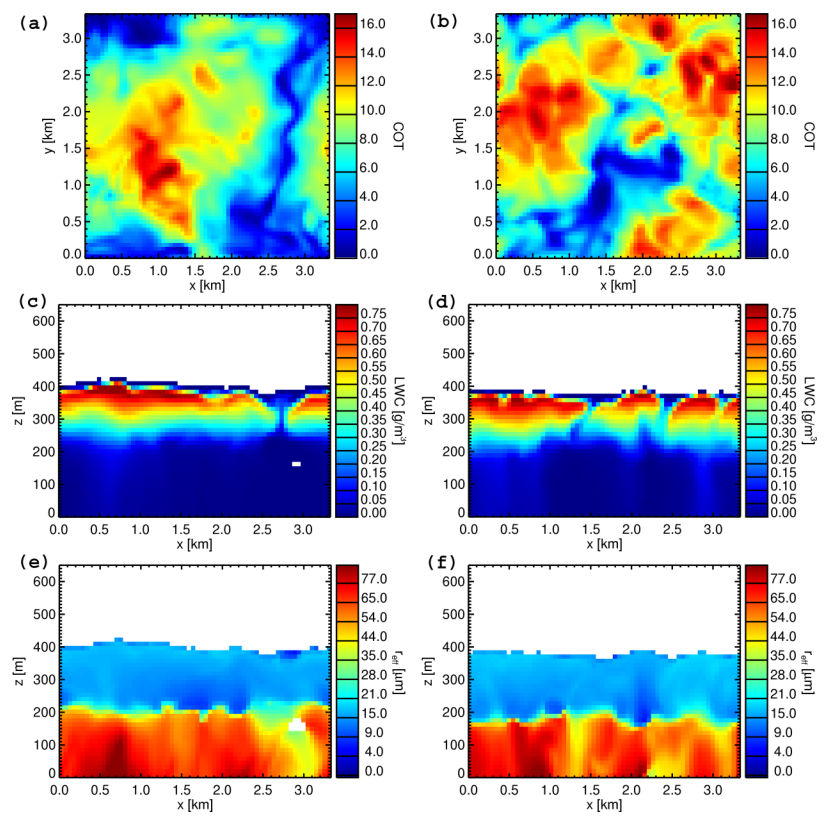

Fig. 3. Cloud data from large eddy simulations of marine stratocumulus deck, $64 \times 64 \times 64$ boxes, $52.5 \times 52.5 \mathrm{~m}$ horizontal resolution, vertical grid spacing varies between 6 and $100 \mathrm{~m}$ : (left) 2 p.m. local time and (right) 6 p.m. local time. Cloud optical thickness (COT), domain mean is 7.8 for 2 p.m. (a) and 9.4 for 6 p.m. (b), liquid water content (LWC, c, d), $r_{\text {eff }}(\mathbf{e}, \mathbf{f})$. Drizzle shows up as low LWC $\left(<0.05 \mathrm{~g} / \mathrm{m}^{3}\right)$ below $\sim 200 \mathrm{~m}$ height associated with large effective radius values $(>35 \mu \mathrm{m})$. The $\mathrm{x}-\mathrm{z}$ vertical slices are taken at the $y=1680 \mathrm{~m}$. White areas have $\mathrm{LWC}<0.0001 \mathrm{~g} / \mathrm{m}^{3}$.

represent very pristine conditions. Solar radiation is included in the simulations, for a date of 14 July at a latitude of $33^{\circ} \mathrm{N}$, and the simulation starts at 6 a.m., shortly after sunrise. The simulations produce an overcast marine stratocumulus deck. Over the 12-h period, the simulations show slightly decreasing cloud heights (top and base), increasing optical thickness, and increasing precipitation rate. The model output used here are for two time slices, at 2 and 6 p.m. 2 p.m. matches a typical MODIS overpass time while the $6 \mathrm{p} . \mathrm{m}$. scene is a slightly different scene, with larger domain-average precipitation rate at cloud base $(0.02$ and $0.05 \mathrm{~mm} / \mathrm{h}$ at 2 and 6 p.m.) and optical thickness (7.8 and 9.4 at 2 and 6 p.m.). The optical thickness at the two output times is in the range typically observed for marine stratus by MODIS (Platnick et al., 2003), while the effective radius at cloud top is between 15 and $20 \mu \mathrm{m}$, at the upper end of the expected range, consistent with droplet concentrations being lower than those typically measured.

For the trade cumulus simulation, the model uses 25 broader size bins that span droplet radii mid-points from 1 to $1100 \mu \mathrm{m}$. In this case the grid mesh is $128 \times 128 \times 100$, with uniform horizontal and vertical grid spacing of 100 and $40 \mathrm{~m}$, respectively. The cloud-free aerosol distribution is bimodal with total concentration $105 \mathrm{~cm}^{-3}$, with $15 \mathrm{~cm}^{-3}$ of those in the coarse mode (representing sea salt). The treat-

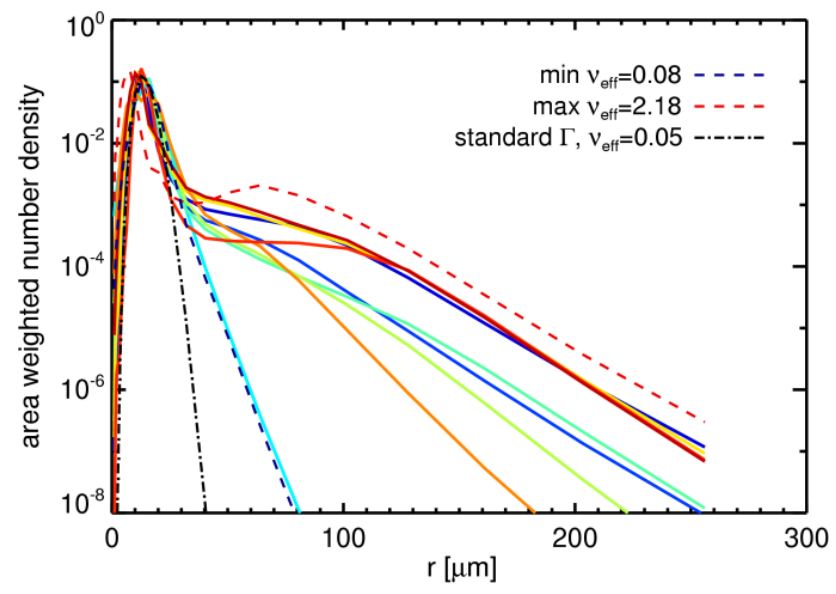

Fig. 4. Sample of 10 drop size distributions from the LES cloud model. All selected distributions have an effective radius of $15 \mu \mathrm{m}$ (solid lines). The classical narrow Gamma distribution $\left(v_{\text {eff }}=0.05\right)$ is marked by the black dot-dashed line. $2 \%$ of all LES distributions are narrower than the one marked by the blue broken line (labeled "min", which is close to another typical standard value $\left.v_{\text {eff }}=0.1\right)$ and $2 \%$ are wider than the one marked by the red broken line ("max").

ment of radiation is extremely simple, with only an imposed, fixed profile that represents clear-sky cooling only. The 24-h simulation produces a field of broken cumulus clouds with average areal coverage of about $20 \%$ and an average droplet concentration (weighted by cloud water mixing ratio) varying between 50 and $60 \mathrm{~cm}^{-3}$. Temporal and spatial variation of precipitation is substantial, with cloud-base domain averages reaching values of $0.02 \mathrm{~mm} / \mathrm{h}$ and greater, while local peaks are two orders of magnitude greater.

Figure 4 shows drop size distributions from one of the cases. All the selected distributions have an effective radius of $15 \mu \mathrm{m}$. The standard assumption for passive cloud property retrievals is a narrow DSD without considering potential drizzle. Such a distribution is represented by the broken black line in Fig. 4, a Gamma distribution with $v_{\text {eff }}=0.05$. All other lines show randomly selected distributions from the cloud data. It is obvious that distributions in this drizzling case are generally wider than the assumed Gamma DSD. Only the narrowest distributions are similar to the standard Gamma distributions.

\subsection{Separation of cloud and drizzle modes}

The reason for the use of narrow analytic functions (e.g. Gamma with fixed variance) for cloud optical properties for radiative transfer simulations is the fact that drop size distributions can be described by modifying a single parameter the effective radius. Likewise, the retrieval only has to estimate a single microphysical parameter representing a DSD at a certain height in the cloud (depending on the penetration 
Table 1. Overview LES simulations.

\begin{tabular}{lllllllll}
\hline LES case & size bins & size range & domain grid & $\Delta x$ & $\Delta z$ & droplet density & optical thickness & rain rate \\
\hline $\begin{array}{lllll}\text { Sc } 2 \text { p.m. } \\
\text { Sc } 6 \text { p.m. }\end{array}$ & 25 & $1-256 \mu \mathrm{m}$ & $64 \times 64 \times 64$ & $52.5 \mathrm{~m}$ & stretched grid & $30 \mathrm{~cm}^{-3}$ & $7.8(\mathrm{mean})$ & $0.02 \mathrm{~mm} / \mathrm{h}$ \\
$\mathrm{Cu}$ & 25 & $1-1100 \mu \mathrm{m}$ & $128 \times 128 \times 100$ & $100 \mathrm{~m}$ & $40 \mathrm{~m}$ & $\sim 50 \mathrm{~cm}^{-3}$ & up to 85 & $0.05 \mathrm{~mm} / \mathrm{h}$ \\
\hline
\end{tabular}

depth). Thus, forward and backward radiative transfer solutions do not have to consider the full variety of realistic size distributions, but can use tables of optical properties as a function of effective radius to obtain approximate properties for varying DSDs within the cloud structure.

Once the size distribution is broadened due to precipitation, in principal the tables of optical properties and forward radiative transfer solutions had to include at least one additional dimension - the width of DSD. For the backward radiative transfer problem - the retrieval - this would in turn increase the number of retrieval unknowns, most likely exceeding the information content in observations from a few spectral channels. This is the reason why all standard retrieval approaches only assume one narrow size distribution (for a vertically homogenous cloud) which is typical for the cloud droplet mode and assume that large droplets can be neglected.

For the radiative transfer simulation of synthetic MODIS observations we do not want to introduce such simplifications as we plan to investigate the impact of that assumption itself. We want to keep the real varying optical properties related to the realistic LES size distributions for each model grid box provided by the LES. Nonetheless, we simplify the variety of real drop size distributions from the cloud model by specifying a narrow cloud droplet mode and a separate wider larger particle drizzle mode without changing the overall microphysical and optical characteristics of the drizzling clouds. With such a bimodal fit, we are able to approximate size distributions like the ones shown in Fig. 4. Apart from numerical reasons for this separation of modes, we are now able to separate the main body of the cloud droplet structure from the drizzle structure and are able to investigate the isolated impact of the drizzle.

Figure 5 shows two examples of this approximation. Two Gamma functions - one representing the cloud mode and one representing the drizzle mode - are fitted (minimizing the cross sectional deviation) to each distribution from the

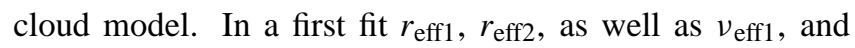
$v_{\text {eff } 2}$ of the Gamma functions are free parameters. Parameters $r_{\text {eff1 }}$ and $v_{\text {eff } 1}$ belong to the small droplet cloud part of the original DSD, $r_{\text {eff } 2}$ and $v_{\text {eff } 2}$ to the drizzle drop mode. These parts are defined as either the droplets left and right of a local minimum in the DSD (two separate modes) or the droplets smaller and larger than twice the effective radius of the complete distribution. A fit is first found for
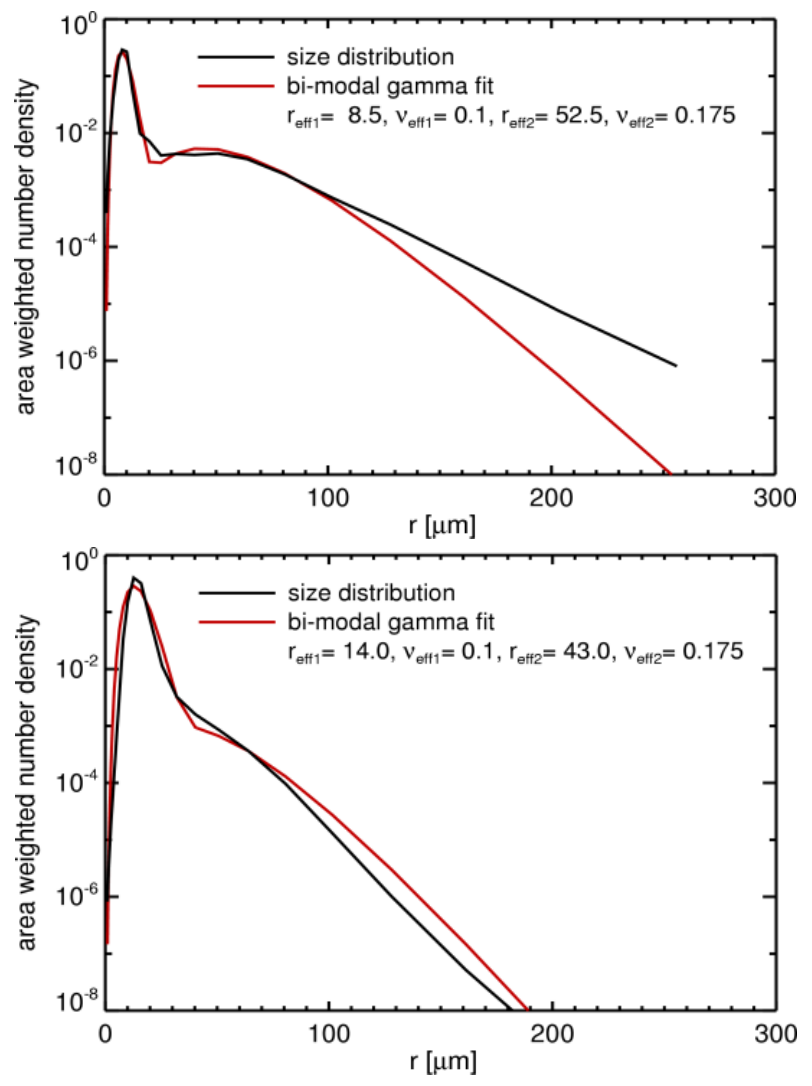

Fig. 5. Examples of bimodal Gamma function fit for two examples with original $r_{\text {eff }}=15 \mu \mathrm{m}$ from LES cloud data. Shown are the fit parameters for the two Gamma functions used.

the cloud mode and successively for the remaining drizzle mode (including the remaining part of the small droplets). To reduce the number of variables for the following radiative transfer simulations, the optimal values for the width of both functions are fixed to the mean values of all distribu-

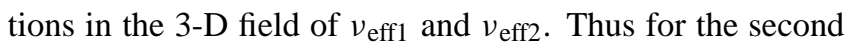
fit, the widths are fixed to 0.1 and 0.175 respectively. In this way, the whole variety of simulated DSD from the model is reduced to an analytic representation: two sets of Gamma functions depending only on $r_{\text {eff1 }}$ and $r_{\text {eff2 }}$. In the first example shown in Fig. 5 (left panel), a well-defined bimodal DSD with $r_{\mathrm{eff}}=15 \mu \mathrm{m}$ is approximated by a cloud effective radius of $8.5 \mu \mathrm{m}$ and a drizzle effective radius of $52.5 \mu \mathrm{m}$; a second 

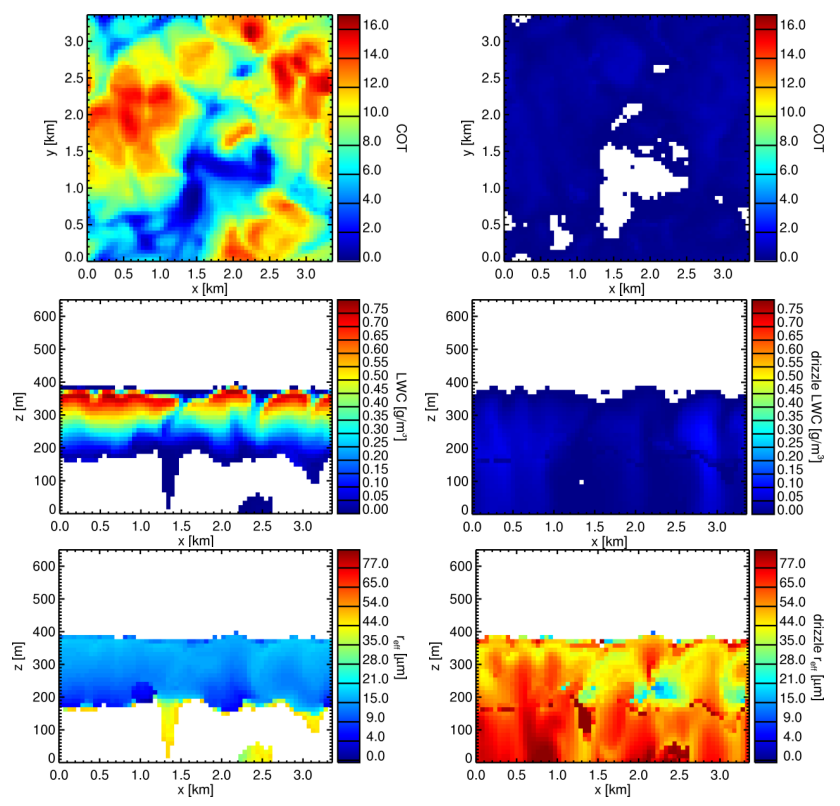

Fig. 6. Separation of drizzle and cloud modes (compare to Figure 3 right column): (Left column) cloud droplet mode, (right column) drizzle drop mode. The mean optical thickness of the cloud droplet mode is 9.1 , and the mean optical thickness of the drizzle mode is 0.4 . White areas have $\mathrm{LWC}<0.0001 \mathrm{~g} / \mathrm{m}^{3}$.

example (right panel) with the same $r_{\text {eff }}$ has no prominent second mode and is approximated by a larger $r_{\text {eff } 1}=14 \mu \mathrm{m}$ and a smaller $r_{\text {eff } 2}=43 \mu \mathrm{m}$. Most distributions in Fig. 4 are approximated well in this way.

The decomposition of the DSD allows more efficient Mie calculations of scattering properties for the distributions. For the two sets of Gamma functions, optical properties are precalculated to form two traditional look-up tables (properties as function of $r_{\text {eff }}$ ) to be used in the radiative transfer calculations. To specify the extinction in each model grid box, in addition to the definition of cloud and drizzle effective radius $r_{\text {eff1 }}$ and $r_{\text {eff2 }}$, the water content is divided into cloud water and the drizzle water (conserving the total LWC). Thus 3-D fields of optical properties representative for the LES cloud simulation can be combined via the look-up tables for each drizzling cloud scene.

The resulting 3-D fields of cloud and drizzle water for the stratocumulus case Sc 6 p.m. are shown in Fig. 6. The spatial separation of the two droplet modes is obvious. Precipitation water (drizzle mode, right column of Fig. 6) below the cloud base around $200 \mathrm{~m}$ extends below the cloud deck (cloud mode, left column). The continuity of the fields of drizzle water content and drizzle effective radius in and outside the cloud layer also seems to corroborate the capability of the separate fits. The effective radius in the cloud mode is still rather large (average of $17 \mu \mathrm{m}$ ); in the drizzle mode values are much larger (average of $60 \mu \mathrm{m}$ ). A few regions show very large "cloud mode" droplets with values around $40 \mu \mathrm{m}$ below the cloud deck (at 0 to $150 \mathrm{~m}$ ). These regions are dominated by the precipitating drops from the cloud deck above, leading to a stronger single large precipitation mode in the size distribution. If this single mode is found at relatively small droplet sizes, it is misinterpreted as being in the cloud mode. Apart from these minor issues, the separation of small cloud droplets and large drizzle drops is physically plausible in this scene and seems to provide an efficient mechanism for determining optical properties for 3-D cloud structures including all details from the LES simulated drop size distributions.

\subsection{Single scattering properties of drop size distributions}

In this section, on the one hand, the quality of the above presented fitting algorithm to separate cloud and drizzle mode will be assessed by means of single scattering properties. On the other hand, the potential of the drizzling cloud's single scattering properties to influence effective radius retrievals independent of the real spatial distribution within the 3-D cloud data is investigated. Figure 7 shows optical properties for size distributions from the stratocumulus cases. For each of the effective radii $(6,8,10,12,17,20,25,30[ \pm 0.1] \mu \mathrm{m})$ 50 sample distributions were randomly selected from the LES data. Three calculations of Mie properties were conducted for each of these distributions: (1) using the original size distribution from the cloud model, (2) assuming the classical narrow single mode Gamma distribution with the same effective radius and $v_{\text {eff }}=0.1$, and (3) using the fitted bimodal Gamma size distributions presented in section 3. In Fig. 7, mean values over the 50 samples are shown for each of the three calculations and for each effective radius for the four MODIS channels. In channels dominated by scattering the properties, the actual size distribution (black lines) can be well approximated by the properties of the narrow standard Gamma distribution (red lines). Only for the asymmetry parameter $g$ do noticeable deviations appear. The stronger the absorption $\left(1-\omega_{0}>0\right)$, the larger the deviations become. In MODIS channel $20(3.7 \mu \mathrm{m})$, not only the asymmetry parameters of the narrow size distributions are clearly different from the actual wide size distributions with the same effective radius, but same is true for the single scattering albedo $\omega_{0}$. While these deviations in $\omega_{0}$ might appear small, they are equivalent to single particle absorptivity differences of $10 \%$ and more. Lower absorptivity $1-\omega_{0}$ of wide size distributions compared to narrow Gamma distributions means that a cloud volume will be more reflective than expected by the retrieval leading to lower effective radius retrievals. This means, while the standard retrieval using narrow monomodal size distributions might still see an increased effective radius for drizzling clouds, this effect tends to mask the real increase in effective particle size. 

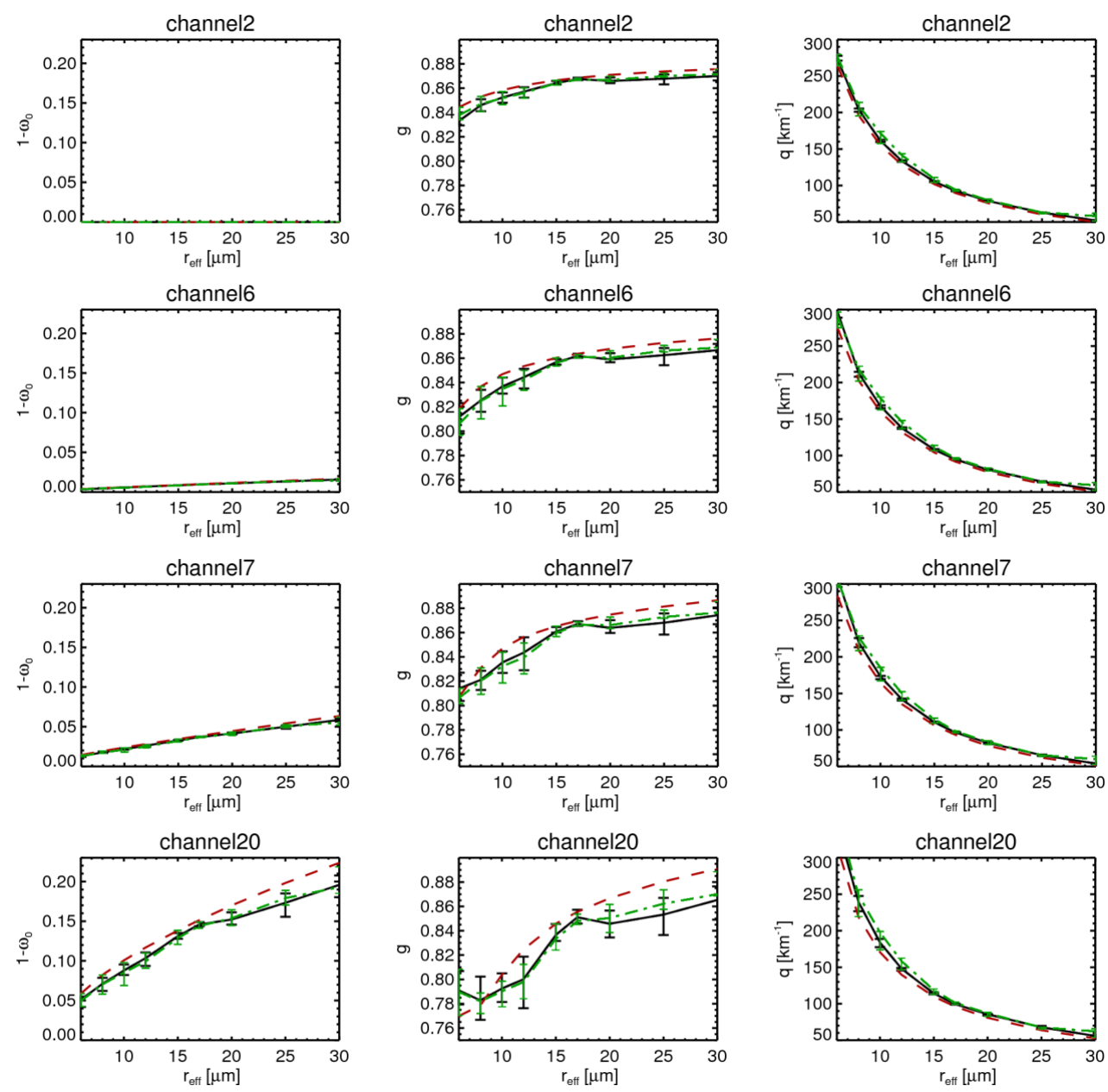

Fig. 7. Examples of Mie properties for MODIS channels $2(0.8 \mu \mathrm{m}), 6(1.6 \mu \mathrm{m}), 7(2.1 \mu \mathrm{m})$, and $20(3.7 \mu \mathrm{m})$. Values are averaged over 50 sample size distributions from the LES cloud data for each effective radius, error bars mark the 16.5 and 83.5 percentile (i.e., $67 \%$ of all cases lie within the bars). Shown are the single scattering albedo (1- $\omega_{0}$, left), the asymmetry parameter (center), and the extinction per unit mass (per $1 \mathrm{~g} / \mathrm{m}^{3}$, right) calculated for the full given size distribution (black lines), for a standard narrow Gamma distribution (red dashed lines, $v_{\text {eff }}=0.1$ ), and for the bimodal Gamma fit described above (green dot-dashed lines).

The possibility of describing single scattering properties of realistic wide (drizzling) size distributions using the narrow single mode Gamma distributions obviously varies with wavelength. Apart from that, Fig. 7 shows that the bimodal fit to the real drop distributions is an excellent approximation with respect to the representation of their single scattering properties (green dot-dashed lines).

At this point it is interesting to check the potential of these differences in optical properties to affect the retrieveable effective radius, neglecting any realistic cloud structure or full radiative transfer. A first estimate is found by applying the optical properties from Fig. 7 in a radiative transfer experiment for a plane-parallel single layer cloud. This way, two different radiance solutions can be obtained from the optical properties for the idealized Gamma size distribution and the average of the real sample distributions of the same effective radius. The successive application of the retrieval to these causes relative underestimates of the effective radius between $13 \%$ (using $1.6 \mu \mathrm{m}$ ) and $17 \%(3.7 \mu \mathrm{m})$. The differences in optical properties in our cases are not as large as the extreme ones discussed in Minnis et al (2004). They freely scale the drizzle part of one size distribution from insitu measurements within a marine stratocumulus by factors up to 96 (multiplying the measured drizzle content). With this maximum scaling factor they reach an absolute increase in $\omega_{0}$ by 0.05 at a large effective radius of $30 \mu \mathrm{m}$ for $3.9 \mu \mathrm{m}$ wavelength, which is about double the impact we see for our realistic size distribution for channel 20 (lower left image of Fig. 7). Only on the basis of this maximum increase in $\omega_{0}$ they estimate a retrieved $r_{\text {eff }}$ to be underestimated by up to $40 \%$ for a retrieval using the $3.9 \mu \mathrm{m}$ wavelength, again about double the impact we estimate on average. 

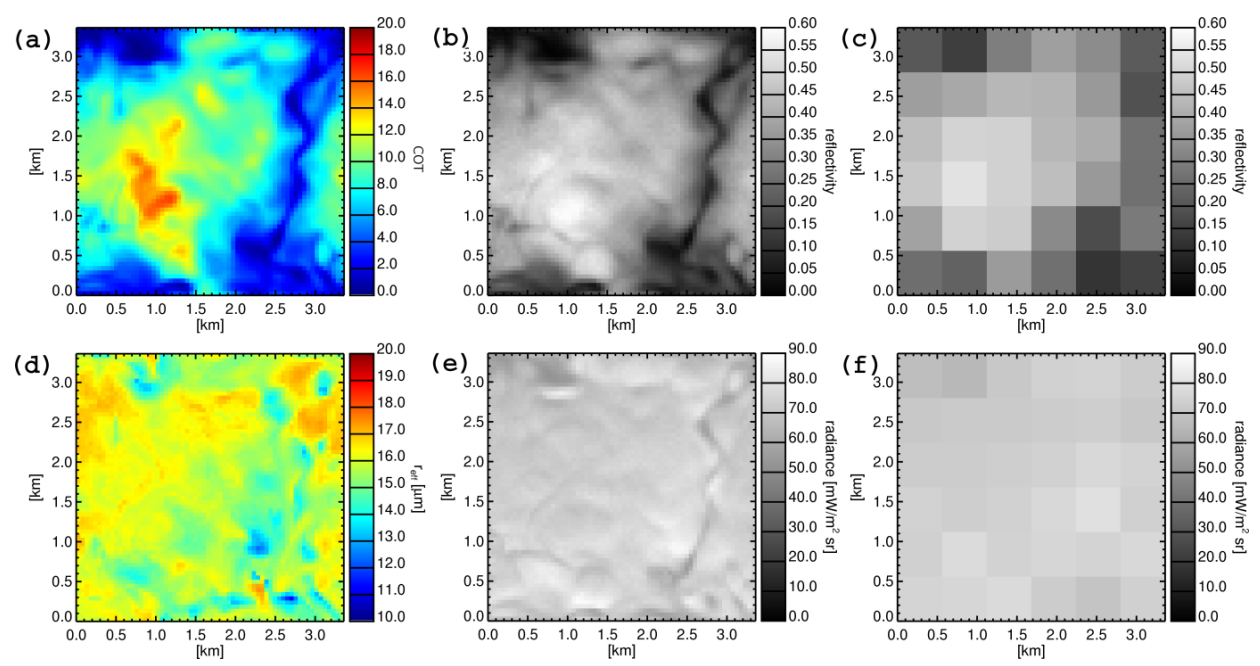

Fig. 8. Examples of simulated satellite observations for the LES stratocumulus scene at 2 p.m. (cf. Fig. 3). Shown is the optical thickness (a), the particle effective radius near cloud top (see text for details, d), the 3-D simulated reflectance in MODIS channels 2 (b, c) and 20 (e, f) at $50 \mathrm{~m}$ and $500 \mathrm{~m}$ resolution ("MODIS" resolution). The solar zenith angle is $45^{\circ}$ (sun from the "south"), the viewing zenith angle $0^{\circ}$ (nadir).

While Minnis et al. (2004) discuss theoretical drizzle impacts, our results are based on a number of realistic size distributions from a physical model simulating drizzle formation. The question how such deviations in the single particle scattering properties affect the full multiply scattered radiation field of a cloud structure with varying density and a mixture of particle sizes, has to be answered by more complete simulations for typical 3-D spatial distributions of these properties, which in our case are defined by the LES cloud model.

\section{Radiative transfer: MODIS image simulation and cloud retrieval}

\subsection{Radiative transfer simulations}

The radiative transfer is simulated using the libRadtran package (Mayer and Kylling, 2005). For the simulation of synthetic MODIS observations, the 3-D Monte Carlo solver MYSTIC is used (Mayer, 2000). MYSTIC accepts two 3D fields of cloud properties and related optical properties tables (usually used to provide ice and water cloud input). This feature is used to set up the separate cloud and drizzle 3-D fields. Optical properties are calculated as a function of effective radius for the narrow cloud droplet mode (Gamma distribution with $v_{\text {eff1 }}=0.1$ ) and the wide drizzle drop mode $\left(v_{\text {eff } 2}=0.175\right)$ using a Mie code. Band models of MODIS channels 2, 6, 7, 20 and $31(10.8 \mu \mathrm{m})$ are used to simulate the radiance at top of atmosphere for a nadir view and solar zenith angle of $45^{\circ}$. To limit the number of possible effects on the retrieval algorithm to a minimum, influences by other atmospheric constituents and the surface are neglected (albedo $=0$, emissivity $=1$ ).

Four different simulations of satellite reflectance are conducted for each of the three LES data sets given in Table 1 with the aim of separating the different effects for analysis: a full 3-D simulation with and without the drizzle field, and a 1-D independent column simulation that excludes horizontal transport effects (again with and without the drizzle). Examples of the simulations are shown in Fig. 8. The simulation is done on the full cloud model resolution $(52.5 \mathrm{~m}$ or 100 $\mathrm{m}$ ) and the results are then averaged to $500 \mathrm{~m}$ spatial resolution. On the usual MODIS cloud product resolution of $1 \mathrm{~km}$ only very few pixels could be obtained, for this reason the following analysis is done on this slightly higher resolution.

In the near-infrared channels (i.e., channel 2, Fig. 8b, c) the optically thicker portions, and especially the illuminated cloud slopes, show high reflectance. Similarly (and thus not shown) for channels 6 and 7. Channel 20 shows the sum of separate solar reflectance and thermal emission contributions (Fig. 8e, f). Due to the almost constant cloud top height, and thus constant thermal background, the simulated channel 20 appears much more homogeneous. The lowest radiances in Fig. 8e are found for shadows close to the very thin cloud portion. This is generally the same region where the thermal surface contribution leads to the largest net emitted radiance (surface temperature $288 \mathrm{~K}$, cloud-top temperature $285.5 \mathrm{~K}$ ). For all cloud scenes $500 \mathrm{~m}$ results are generated for the cloud droplet fraction with and without the precipitation fraction. In addition, independent column simulations of the same cases are provided. This way, 3-D radiative effects due to cross pixel horizontal transport like shadows and bright slopes can be excluded. 

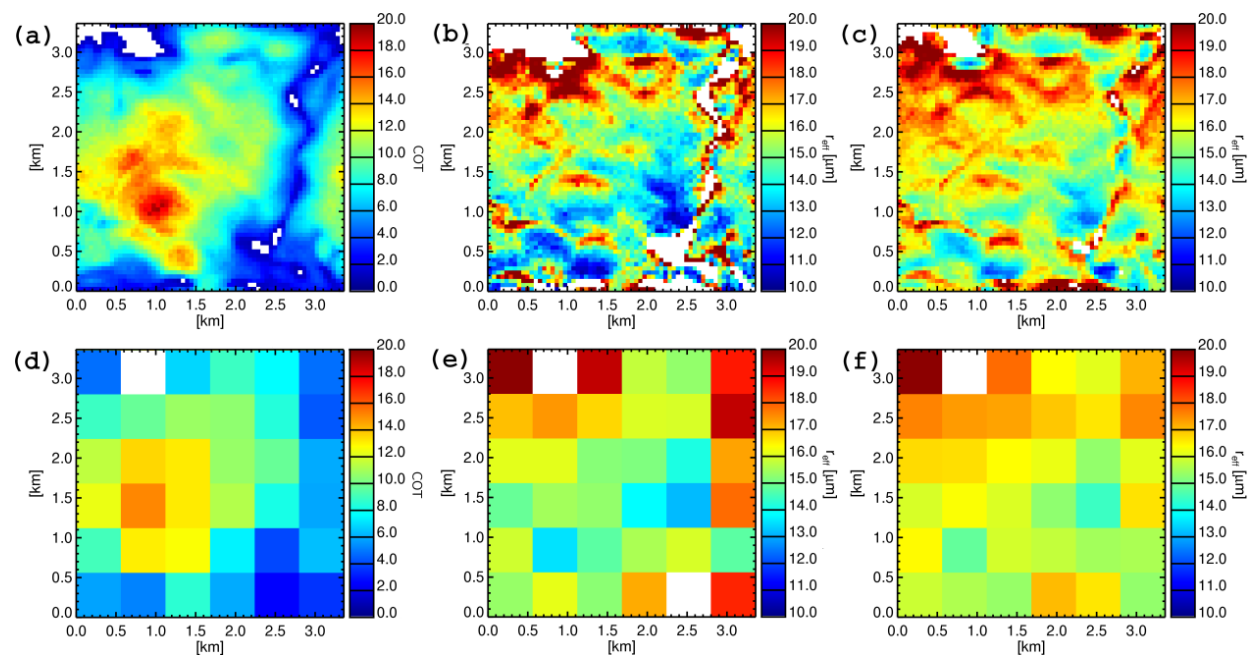

Fig. 9. MOD06 retrieval results for the 3-D simulated stratocumulus images (Fig. 8). Retrieved optical thickness on $50 \mathrm{~m}$ (a) and $500 \mathrm{~m}$ (d), effective radius from $0.86 / 2.1 \mu \mathrm{m}(\mathbf{b}, \mathbf{e})$, and from $0.86 / 3.7 \mu \mathrm{m}(\mathbf{c}, \mathbf{f})$. For white areas no retrieval is found.

\subsection{Cloud retrieval}

All operational retrievals use the different sensitivities to cloud optical thickness and droplet effective radius at predominantly scattering wavelengths in the visible/nearinfrared and more absorbing near shortwave/ midwaveinfrared wavelengths, respectively (e.g., MODIS: Platnick et al., 2003; or Meteosat EUMETSAT/CMSAF: Roebeling et al., 2006; several sensors: Minnis et al., 1995). In the MODIS algorithm (generically referred to by the MODIS Terra product name, MOD06) several independent retrievals of effective radius are done using different combinations of the visible/near-infrared and/or channels 6, 7, and 20 (where liquid water absorption becomes progressively important) all assuming a narrow mono-modal particle size distribution as well as vertically homogeneous cloud layers. Both assumptions might lead to errors for cloud scenes generating drizzle as they are particularly incorrect in these situations.

Instead of using the available plane-parallel vertically homogenous (PPH) cloud model vs. radiance libraries in the MODIS MOD06 algorithm, the libraries were re-generated in the same way (PPH) using the libRadtran package to eliminate spurious effects due to model inconsistencies. In addition, by directly providing libRadtran simulated emissivity values to the modified MOD06 retrieval the real world uncertainty due the operational algorithm's emission correction of the measured $3.7 \mu \mathrm{m}$ radiance is avoided. The measured radiance in the $3.7 \mu \mathrm{m}$ channel includes a significant thermal emission component, which is usually estimated from the MODIS $11 \mu \mathrm{m}$ window (Menzel et al., 2008).

The retrieval of optical thickness and effective radius is explained elsewhere (Nakajima and King, 1990). As with MOD06, three separate size retrievals are performed using simulations of the MODIS $0.86 \mu \mathrm{m}$ channel along with the
$1.6 \mu \mathrm{m}, 2.1 \mu \mathrm{m}$ or $3.7 \mu \mathrm{m}$ channel simulations. The operational MOD06 algorithm interpolates across the library geometry space for the given solar and sensor zenith angles and the relative azimuth. In this study, however, the libraries were custom generated to match the model geometry and no interpolation is therefore needed.

\section{Results}

Figure 9 shows a set of results of the MOD06 retrievals applied to the 3-D simulated MODIS observation for the 2 p.m. stratocumulus case. Now this type of operational retrieval for MODIS scenes with and without drizzle can be compared to the truth in our original LES cloud data sets, with and without drizzle as generated in Sect. 2.1.

Optical thickness retrievals can be directly compared to the true values of optical thickness, which can be derived from water content and drop size distributions from the Sect. 2.1., but an estimate for the "true" particle size is also required. Because effective radius in real clouds usually varies with height, and each of the MODIS retrievals has a certain penetration depth into the cloud layer, it is more difficult to provide this. It has been shown that the expected size is approximated by a reflectance weighting that is a function of the size profile, geometry, and spectral band (Platnick, 2000). Rather than replicate the spectral reflectance weightings across the model field, we have opted to instead use an easier extinction weighting (down to a maximum optical depth of 5, cloud top layer effective radius, Fig. 8d). However, the more relevant point is not the determination of this reference value, but the differences between the three spectral retrievals and the different scenes optionally including drizzle and/or 3-D effects. 
Table 2. Average values over two analyzed stratocumulus scenes of true and retrieved values of effective radius (three values using $0.86 \mu \mathrm{m}$ and the channel given in the table) and cloud optical thickness.

\begin{tabular}{lllllll}
\hline $\begin{array}{l}\text { domain } \\
\text { average }\end{array}$ & $\begin{array}{l}\text { "true" } \\
r_{\text {eff }}[\mu \mathrm{m}]\end{array}$ & $\begin{array}{l}r_{\text {eff }}[\mu \mathrm{m}] \\
1.6\end{array}$ & $\begin{array}{l}r_{\text {eff }}[\mu \mathrm{m}] \\
2.1\end{array}$ & $\begin{array}{l}r_{\text {eff }}[\mu \mathrm{m}] \\
3.7\end{array}$ & $\begin{array}{l}\text { true } \\
\text { COT }\end{array}$ & $\begin{array}{l}\text { COT } \\
\text { retr. }\end{array}$ \\
\hline 1-D nodriz & 16.16 & 13.83 & 16.15 & 16.49 & 8.46 & 9.38 \\
1-D driz & 16.44 & 14.11 & 16.42 & 16.58 & 8.75 & 9.68 \\
3-D nodriz & 16.16 & 13.67 & 16.28 & 16.65 & 8.46 & 9.26 \\
3-D driz & 16.44 & 13.95 & 16.57 & 16.75 & 8.75 & 9.55 \\
\hline
\end{tabular}

Table 3. Standard deviation over two analyzed stratocumulus scenes of true and retrieved values of effective radius (three values using $0.86 \mu \mathrm{m}$ and the channel given in the table) and cloud optical thickness.

\begin{tabular}{|c|c|c|c|c|c|c|}
\hline $\begin{array}{l}\text { standard } \\
\text { deviation }\end{array}$ & $\begin{array}{l}\text { "true" } \\
r_{\text {eff }}[\mu \mathrm{m}]\end{array}$ & $\begin{array}{l}r_{\mathrm{eff}}[\mu \mathrm{m}] \\
1.6\end{array}$ & $\begin{array}{l}r_{\text {eff }}[\mu \mathrm{m}] \\
2.1\end{array}$ & $\begin{array}{l}r_{\text {eff }}[\mu \mathrm{m}] \\
3.7\end{array}$ & $\begin{array}{l}\text { true } \\
\text { COT }\end{array}$ & $\begin{array}{l}\text { COT } \\
\text { retr. }\end{array}$ \\
\hline 1-D nodriz & 0.68 & 3.86 & 1.01 & 0.55 & 2.98 & 3.35 \\
\hline 1-D driz & 0.75 & 3.97 & 1.04 & 0.58 & 3.10 & 3.48 \\
\hline 3-D nodriz & 0.68 & 4.13 & 1.87 & 0.98 & 2.98 & 3.33 \\
\hline 3-D driz & 0.75 & 4.27 & 1.98 & 1.01 & 3.10 & 3.44 \\
\hline
\end{tabular}

Drizzle is either included into the simulation of MODIS observations or not by including or removing the drizzle drop size mode and the related drizzle water content from the 3-D cloud fields (see Sect. 2.1). Consequently two sets of true values can be derived (with and without the drizzle fraction of the cloud). 3-D effects can be deactivated by doing independent column radiative transfer simulations of the MODIS observations for each vertical cloud field column instead of full 3-D simulations. Without 3-D effects, of course, the sets of true values stay the same as for the full 3-D simulations.

\subsection{Base case: overcast stratocumulus}

In Fig. 9a-c the MOD06 retrievals are run on the full $50 \mathrm{~m}$ resolution for one of the stratocumulus cases. The retrievals show a slight shift of the maximum optical thickness towards the sun. The average retrieved optical thickness slightly overestimates the true value for the 1-D as well as the 3-D simulated observation. The effective radius retrievals show much stronger sensitivity for illumination effects. In shadowed areas the effective size is strongly overestimated while it is underestimated for the illuminated parts. Using $1.6 \mu \mathrm{m}$ no retrievals are found for some of these areas (additional white pixels). This is due to ambiguities appearing in the assignment of effective radius and optical thickness in the PPH retrieval libraries. Figure 9d-f show the retrievals for the same case using simulated radiances at $500 \mathrm{~m}$ resolution. 3-D effects which are generally small for these cases, widely disappear due to the averaging over large pixels.

The following analysis of mean values and standard deviations combines the $500 \mathrm{~m}$ results for both overcast simu- lations; a sample of 72 overcast stratocumulus pixels is thus examined. Tables 2 and 3 show average retrievals and related standard deviations. Only very small 3-D impact can be seen in Table 2. Comparing 1-D and 3-D simulations the average values change only between -0.15 (for retrieval $0.86 / 1.6 \mu \mathrm{m}$ ) to $0.16 \mu \mathrm{m}$ (retrieval $0.86 / 3.7 \mu \mathrm{m}$ ), and even the standard deviation shows only a small increase in scatter. The mean retrieved values also hardly change due to drizzle either (between 0.1 to $0.3 \mu \mathrm{m}$ increase in $r_{\text {eff }}$ with drizzle). Still there are some interesting details to be noted:

The cloud deck in both cases has a consistent vertical profile as far as the cloud droplet mode is concerned; droplet effective radii are increasing with height (Fig. 6). Thus the retrievals - generally neglecting any vertical inhomgeneity which have a deeper optical penetration depth show smaller average effective radii characteristic of droplets at lower altitudes. The "true" values averaged over the cloud top layer give a reasonable match to the $0.8 / 2.1 \mu \mathrm{m}$ retrieval. The retrievals using $1.6 \mu \mathrm{m}$ are a bit smaller and the one using $3.7 \mu \mathrm{m}$ are larger, because they are more sensitive to effective radius in lower and higher cloud layers, respectively. These differences demonstrate the potential to retrieve information on the cloud profile from the different spectral retrievals (e.g. Chang and Li, 2003; Chen et al., 2008). The scatter in the 1 -D no-drizzle case is smallest for the $3.7 \mu \mathrm{m}$ effective radius retrievals. This might on the one hand be due to the fact that the inhomogeneity of particle size within the $500 \mathrm{~m}$ pixel is smallest near the cloud top. On the other hand, as the MODIS retrieval simultaneously retrieves optical thickness and effective radius from two channels the errors of each 
Table 4. Domain average values for the cumulus scene of true and retrieved values of effective radius (three values using $0.86 \mu \mathrm{m}$ and the channel given in the table) and cloud optical thickness.

\begin{tabular}{|c|c|c|c|c|c|c|}
\hline $\begin{array}{l}\text { domain } \\
\text { average }\end{array}$ & $\begin{array}{l}\text { "true" } \\
r_{\text {eff }}[\mu \mathrm{m}]\end{array}$ & $\begin{array}{l}r_{\mathrm{eff}}[\mu \mathrm{m}] \\
1.6\end{array}$ & $\begin{array}{l}r_{\mathrm{eff}}[\mu \mathrm{m}] \\
2.1\end{array}$ & $\begin{array}{l}r_{\mathrm{eff}}[\mu \mathrm{m}] \\
3.7\end{array}$ & $\begin{array}{l}\text { true } \\
\text { COT }\end{array}$ & $\begin{array}{l}\text { COT } \\
\text { retr. }\end{array}$ \\
\hline 1-D nodriz & 19.87 & 11.02 & 14.71 & 21.27 & 2.19 & 1.71 \\
\hline 1-D driz & 58.42 & 10.23 & 14.58 & 22.14 & 2.26 & 1.75 \\
\hline 3-D nodriz & 19.87 & 7.41 & 11.72 & 21.28 & 2.19 & 1.06 \\
\hline 3-D driz & 58.42 & 7.73 & 11.65 & 21.93 & 2.26 & 1.09 \\
\hline
\end{tabular}

Table 5. Standard deviation for the cumulus scene of true and retrieved values of effective radius (three values using $0.86 \mu \mathrm{m}$ and the channel given in the table) and cloud optical thickness.

\begin{tabular}{lllllll}
\hline $\begin{array}{l}\text { standard } \\
\text { deviation }\end{array}$ & $\begin{array}{l}\text { "true" } \\
r_{\text {eff }}[\mu \mathrm{m}]\end{array}$ & $\begin{array}{l}r_{\text {eff }}[\mu \mathrm{m}] \\
1.6\end{array}$ & $\begin{array}{l}r_{\text {eff }}[\mu \mathrm{m}] \\
2.1\end{array}$ & $\begin{array}{l}r_{\text {eff }}[\mu \mathrm{m}] \\
3.7\end{array}$ & $\begin{array}{l}\text { true } \\
\text { COT }\end{array}$ & $\begin{array}{l}\text { COT } \\
\text { retr. }\end{array}$ \\
\hline 1-D nodriz & 9.00 & 9.20 & 9.91 & 6.91 & 9.33 & 13.27 \\
1-D driz & 48.76 & 8.75 & 9.70 & 7.47 & 9.32 & 13.45 \\
3-D nodriz & 9.00 & 6.98 & 9.03 & 8.47 & 9.33 & 6.46 \\
3-D driz & 48.76 & 7.32 & 9.38 & 8.60 & 9.32 & 6.56 \\
\hline
\end{tabular}

retrieved parameter always affect the other parameter as well. In this respect, an advantage of the retrieval using $3.7 \mu \mathrm{m}$ is the better orthogonality of the two solutions; thus the retrieved effective radius is nearly independent from the optical thickness (e.g., Platnick et al., 2001). This independence from biases in the optical thickness retrieval might contribute to smaller variability in the $3.7 \mu \mathrm{m} 1-\mathrm{D}$ retrieval.

Moving on to the 3-D results, the scatter of effective radius retrievals increases due to horizontal photon transport (shadows, bright slopes) though the effect is relatively benign. Interestingly the relative increase in scatter is greatest for the $3.7 \mu \mathrm{m}$ retrieval. Due to greater absorption the horizontal photon transport is much weaker in this channel compared to 1.6 and $2.1 \mu \mathrm{m}$. The greater absorption causes sharper shadow effects and thereby stronger 3-D impact on the scatter. Mean values over all pixels are practically unchanged.

Adding the drizzle mode to the cloud data set has only minor impact. A slight increase of the retrievals using 1.6 and $2.1 \mu \mathrm{m}$ is detectable in the average values as well as in the individual retrievals while even smaller sensitivity is seen for the $3.7 \mu \mathrm{m}$ retrievals. Drizzle mainly forming in the central and lower height levels of the cloud is only detectable in the deeper penetrating retrievals while the retrieval that sees the topmost cloud layers changes least. The overall impact is minimal ( $0.3 \mu \mathrm{m}$ on average) and hardly large enough to make drizzle formation directly detectable from effective radius retrievals in this case. Chen et al. (2008) show that for heavy drizzle, the impact can lead to a reversal of the usually positive droplet size gradient with height (consistent with in- creasing size retrievals with increasing wavelength) towards a neutral or negative size gradient with height (as apparently seen in Fig. 2) though their study involved analytic ad hoc size profiles and were not developed from model fields or in situ data.

There is obviously little drizzle sensitivity in this case. The cloud is thick enough to obscure the drizzling lower cloud layers and the drizzle rain rate is at the same time rather small ( 0.02 and $0.05 \mathrm{~mm} / \mathrm{h}$ average at cloud base in the two scenes) compared to reported cases where drizzle formation seems to have impact on MODIS retrievals ( $>0.1 \mathrm{~mm} / \mathrm{h}$ in Chen et al., 2008).

\subsection{Complex case: scattered cumulus}

Beyond the just discussed base case, an overcast stratocumulus deck with a typical marine diurnal cycle that does not show sensitivity of cloud retrievals to drizzle, we now investigate a second case with heavier precipitation and greater horizontal heterogeneity. In the broken cumulus case introduced in Sect. 2, localized heavy drizzle, with peak precipitation exceeding $1 \mathrm{~mm} / \mathrm{h}$ in some model columns is in some places directly visible from the simulated satellite perspective, as the precipitation shears from its generating cells, which in some instances have largely dissipated. Figure 10 shows the 2-D fields of optical thickness and cloud top layer effective radius from the LES as well as the 3-D simulated high resolution nadir radiance field for the $2.1 \mu \mathrm{m}$ channel. The fields of drizzle and dissipating clouds show up as dark red areas in Fig. 10b (effective radius $\gg 30 \mu \mathrm{m}$ ). As before simulated MODIS observations at $500 \mathrm{~m}$ resolution are 

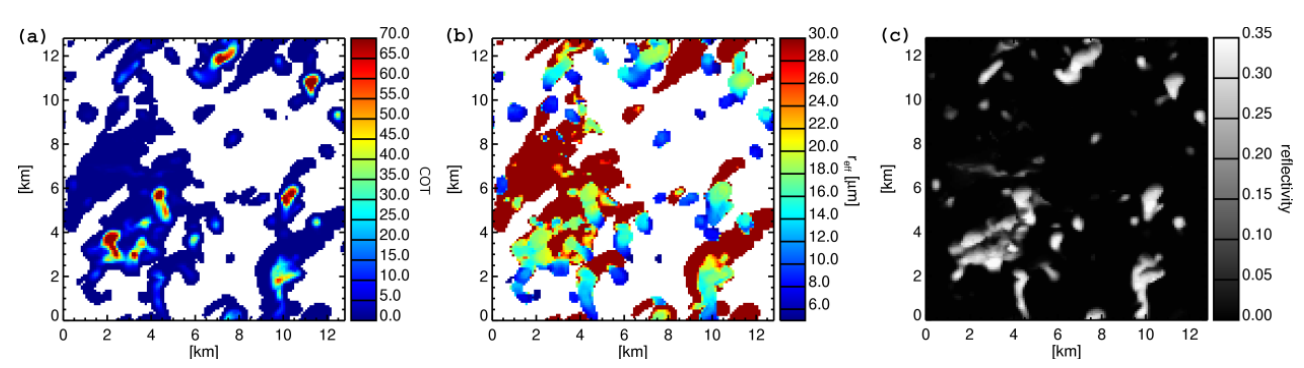

Fig. 10. Cumulus field - optical thickness (a), cloud top layer effective radius (b), simulated reflectivity in channel 7 (2.1 $\mu \mathrm{m})$. The horizontal resolution is $100 \mathrm{~m}$. Maximum values are cut off for reasons of presentation; white areas in (a) and (b) show COT=0.
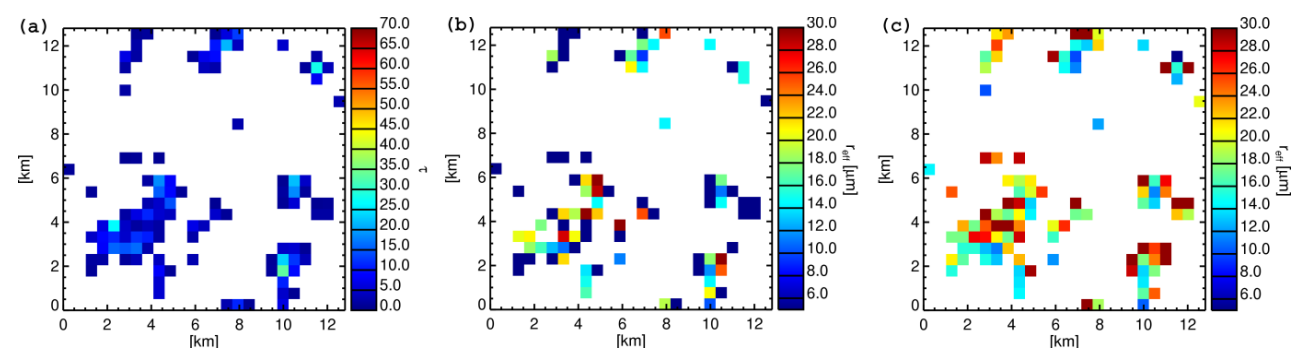

Fig. 11. MOD06 retrieval for 3-D cumulus simulations ( $500 \mathrm{~m}$ resolution) of optical thickness (a), effective radius from $0.86 / 2.1 \mu \mathrm{m}$ (b), effective radius from $0.86 / 3.7 \mu \mathrm{m}$ (c). For white areas no retrieval is found.

processed through the MOD06 retrievals. Figure 11 shows these retrievals of optical thickness and effective radius using $0.86 / 2.1 \mu \mathrm{m}$ and $0.86 / 3.7 \mu \mathrm{m}$, Tables 4 and 5 show the domain average values and their standard deviation.

In this scattered cumulus case an important additional factor is the number of pixel retrievals possible. If the reflected signal in one of the channels is not part of the PPH cloud model vs. radiance libraries (e.g. the signal is too low) or the combination of two channel's reflectivities is outside the covered retrieval space a non-retrieval is issued. In addition, an unambiguous retrieval is not possible for all of these cloudy pixels. This problem already shows up in the optical thickness retrieval, as seen in Table 4 . The retrieval substantially underestimates the domain average even for the 1-D simulated observations. Mainly this underestimation is caused by areas of small optical thickness (e.g. in the drizzle areas) for which no retrievals are found on the $500 \mathrm{~m}$ resolution, but which do have a large mean "true" effective radius due to the fact that they are covered by drizzle. This effect manifests itself also in the standard deviation which is much larger for the LES optical thickness field than for the retrieved fields due to the missing small values in the latter. Moving to full 3-D simulated MODIS data the underestimation of the real optical thickness increases. 3-D illumination effects and diffusion of radiation away from the cloud patches obviously reduces the reflected radiance and thus the retrieved optical thickness. These findings have not to be confused with results of others on the impact of cloud inhomogeneity and 3$D$ effects on effective radius retrievals, which are valid for effective radius values in the range of cloud particles (e.g. Marshak et al., 2006; Kato et al., 2006). Here the result is dominated by the pixels with drizzle sized particles and thus very large effective radii and the way the particular retrieval deals with these areas of very low optical thickness.

In contrast to the overcast stratocumulus case, the LES domain averages of the cloud top layer effective radius are dominated by the presence of drizzle. The domain average is larger than $50 \mu \mathrm{m}$ including the drizzle mode while it is only about $20 \mu \mathrm{m}$ without. This difference is evident in any of the retrievals, as no retrievals are possible for the large areas with drizzle but no cloud water content at cloud top, because they are too dark to be considered cloud. Only a minor increase of droplet size of about 0.5 to $1 \mu \mathrm{m}$ is found by the $3.7 \mu \mathrm{m}$ retrieval once the drizzle is included (for 1$\mathrm{D}$ and 3-D MODIS simulations). Also the impact of 3-D radiative transfer is hardly detectable, both for the averages and the standard deviations. The 3-D impact is different for the 1.6 and $2.1 \mu \mathrm{m}$ retrievals. The domain average retrieved sizes in some cases even decrease, when drizzle is added. This apparently contradictory result is a consequence of a few additional, but small, retrievals. These retrievals appear in regions close to the cloud edges where especially large retrieved sizes are visible in the $3.7 \mu \mathrm{m}$ data (compare Fig. 11b and c). These locations indicate optically thin layers of large drops (visible in the most absorbing channel) covering a layer of much smaller cloud droplets (detected by the more penetrative channels). Alternatively, the size of these small values is at the low end of the effective radius range covered by 
the MOD06 retrieval libraries, and thus the different 3-D response of the retrieval at $3.7 \mu \mathrm{m}$ could also be an artifact of misinterpretations of the "observed" radiance at the limits of the look-up tables. If only the pixels are considered which produce retrievals for all three channels, the different 3-D response of the retrievals at $3.7 \mu \mathrm{m}$ disappears and the average effective radius increases for all three (not shown).

The impact of 3-D effects is only obvious for the 1.6 and $2.1 \mu \mathrm{m}$ retrievals. The retrieved effective radius is reduced by several micrometers for both (Table 4). This reduction could be due to cloud slopes illuminated by the sun then misinterpreted as small particles while for the related shadow regions no retrievals are derived at all (compare Figs. 10c and 11b), but again the number of spurious small retrievals increases for the 3-D simulated MODIS observations compared to the 1-D simulations and reduces the domain average additionally.

\section{Discussion and outlook}

Results of a model study on the sensitivity of the MODIS operational cloud effective radius retrievals to the presence of drizzle and 3-D radiative transfer are presented. This study is done using LES cloud data sets with detailed microphysics, through the simulation of synthetic MODIS images with a Monte Carlo model, and the successive application of the MODIS retrieval to the simulated observations. Each droplet size distribution of each grid box from the LES is separated into precipitation and cloud droplet modes. In this way, the Mie scattering calculations needed for the radiative transfer simulations are provided via two look-up tables, one for the cloud and one for the drizzle fraction with single scattering properties as a function of two effective radius values. The realistic full 3-D information of single scattering properties given by the LES is conserved.

A preliminary check of the optical properties within our LES microphysics data (as well as the mentioned lookup tables) reveals typical impact of the large drizzle droplets part of the drop size distribution on the single scattering properties, similar to findings of Minnis et al. (2004). The large droplets lead to reduced absorption (increased single scattering albedo) and a decrease in forward scattering compared to the narrow drop size distributions usually used, e.g., in standard cloud retrievals. From the satellite remote sensing point of view, both of these effects would lead to larger reflectivities and once these are used in a retrieval (assuming narrow drop size distributions) to an underestimation of true effective radius. Although this effect obviously tends to mask the detection of large particles, still no conclusive answer to this question can be given without including the typical sizes, fraction, and distribution of drizzle droplets in a typical cloud 3-D structure. Still large drizzle droplets, though underestimated in size, could affect the retrieved values.
Our setup allows to deactivate the drizzle influence for a given cloud scene, by omitting the drizzle mode including its share of the water content for each cloud grid box. Impacts of drizzle and 3-D radiative transfer can thus be investigated separately by systematic modification of certain parts of the simulated testing environment (drizzle or no drizzle, 1-D or 3-D radiative transfer).

We investigate two different types of boundary layer clouds: (1) a case of a drizzling fully overcast marine stratocumulus deck at two stages during a diurnal cycle; and (2) a more complex cloud scene of a drizzling cumulus field. For both cloud types the impact of drizzle formation on the MODIS retrieval is very small. The sensitivity to the drizzle size drops in the cloud deck is too small to explain contrasts like that seen in Fig. 1 let alone a clear detection of drizzle. The lack of substantial cloud gaps (i.e., the overcast nature of the scene) prevents a direct view of drizzle below the cloud layers for the stratocumulus case while in the cumulus case the large areas of theoretically openly visible drizzle remains undetected as the reflectance from these regions is too low to produce a retrieval.

The effect of 3-D radiative transfer is only pronounced for the scattered cumulus case and the size retrievals using channels 6 and $7(1.6$ and $2.1 \mu \mathrm{m})$. The further analysis of the cumulus case suggests some additional sources of difference between the different MOD06 effective size retrievals. Nonretrievals, which are more likely the shorter the wavelength of the absorbing channel and the weaker the absorption is, can have a significant impact on domain averages. This effect can be increased by 3-D effects through the different sensitivity to shadowing and illumination for the three retrievals. In addition, most likely spurious small pixel retrievals in situations close to ambiguous solutions in the retrieval space further contribute to a lack of retrievals.

In this context the apparent differences to results of Marshak et al. (2006) or Kato et al. (2006) have to be mentioned once more. While these also evaluate the impact of 3-D effects and inhomogeneity on effective radius retrievals by means of LES cloud data and 3-D radiative transfer simulations, they investigate cloud particle sized effective radius variations and idealized, exemplary retrievals. In particular for the cumulus case the observed effects are due to large precipitation sized particles' spatial distribution and the response of an operational retrieval to it (in particular the processing of dark optically thin areas). Our stratocumulus case results, on the other hand, are comparable to their finding that for such homogeneous clouds hardly any 3-D or inhomogeneity impact on the effective radius is observable.

Although this investigation includes only 3 cloud scenes, we consider the two stratocumulus scenes typical for daytime marine stratocumulus. The optical thickness and effective radius are in the range typically observed for this type of cloud likely to produce drizzle, as can be seen in the MODIS data given in Fig. 12. In addition, as well the global averages of effective radius and optical thickness given in Leon 


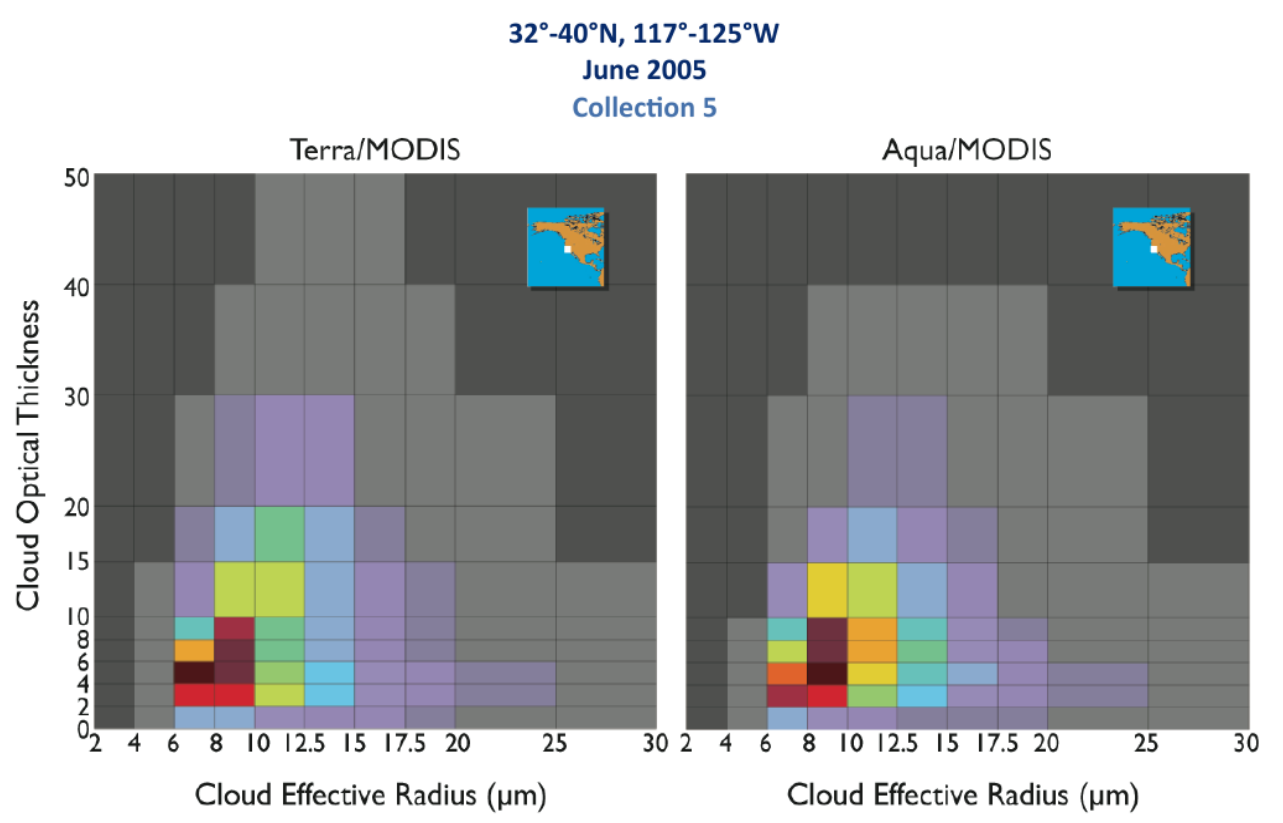

Fig. 12. Probability density function of cloud optical thickness and effective radius for low level liquid water clouds as retrieved by MODIS for June 2005 over the region shown in the little map. Dark red and black colors show the most frequent situations, while green, blue and grey show decreasing occurrence. On the left the data from the TERRA overpasses in the morning is shown, on the right from the AQUA overpasses in the afternoon.

et al. (2008) for marine stratocumulus are close to our average values for our stratocumulus cases (effective radius $16 \mu \mathrm{m}$ and optical thickness 8.5), as their numbers for the global average drizzle intensities in precipitating stratocumulus (our cases $0.04 \mathrm{~mm} / \mathrm{h}$ ) with the most globally occurring rain rates clearly below the (local) peak values in our cases (peaks exceed 0.2 and $1 \mathrm{~mm} / \mathrm{h}$ for the stratocumulus and cumulus scenes here). Drizzle formation as well as 3-D effects in clouds with larger scale dynamical organization, like the cell structures in Fig. 1, can probably produce larger horizontally averaged rain rates than the ones in the stratocumulus simulations used or larger 3-D effects strongly depending on the illumination geometry. Nonetheless, we showed that in situations of broken cloudiness and drizzle regions which are not covered by clouds a lot of other effects can contribute to the domain average values of effective radius, and a general detectability of drizzle cannot be assumed either. For the broken cloud scene we consider, no strong sensitivity of the MODIS retrieval to drizzle is found. 3-D effects, on the other hand, show the potential to introduce large discrepancies in retrieved effective radius between the three different retrievals; although in the case we examine these have a different effect than for the case presented in figures 1 and 2 . The application of our testing setup to more organized cloud situations is left for further study.

We exclude the possibility that the MODIS effective size retrievals are affected by the non-representation of wide (drizzling) droplet distribution in the retrieval itself at least for the cloud scenes we consider. We see no sign that pre- sumably typical daytime drizzle for very clean daytime marine stratocumulus can be detected in the "profile" of MODIS effective size retrievals as Chang and $\mathrm{Li}$ (2003) or Chen et al. (2008) observe. Given the fact that a large fraction of all marine boundary layer clouds produces drizzle, Leon et al. (2008) estimate up to $40 \%$, it is of course imaginable that still a notable number of cloud cases produces rain rates large enough to be detected. All these considerations, in general, still leave the additional possibility that precipitation processes could be detected because of more indirect relation with the retrievable effective radius. Without the need for a direct sensitivity of standard retrievals to drizzle sized droplets the small cloud droplet mode itself could well show a general, and correctly retrieved, increase in effective size in a cloud producing drizzle.

Acknowledgements. T. Zinner was supported by a German Research Foundation (DFG) Fellowship and the NASA visiting scientists program. We thank M. Hagen for his helpful comments and two anonymous reviewers for their critical reviews which helped to improve the final manuscript.

Edited by: J. Quaas

\section{References}

Ackerman, A. S., Kirkpatrick, M. P., Stevens, D. E., and Toown, O. B.: The impact of humidity above stratiform clouds on indirect aerosol climate forcing, Nature, 432, 1014-1017, doi:10.1038/nature03174, 2004. 
Ackerman, A. S., Toon, O. B., Stevens, D. E., and Coakley, Jr., J. A.: Enhancement of cloud cover and suppression of nocturnal drizzle in stratocumulus polluted by haze. Geophys. Res. Lett., 30, 1381, doi:10.1029/2002GL016634, 2003.

Ackerman, S. A., Strabala, K. I., Menzel, W. P., Frey, R. A., Moeller, C. C., and Gumley, L. E.: Discriminating clear-sky from clouds with MODIS. J. Geophys Res.-Atmos., 103(D24), 32141-32157, 1998.

Cahalan, R. F., Ridgway, W., Wiscombe, W. J., Gollmer, S., and Harshvardhan:, Independent pixel and Monte Carlo estimates of stratocumulus albedo, J. Atmos. Sci., 51, 3776-3790, 1994.

Chang, F.-L. and Li, Z.: Retrieving vertical profiles of watercloud droplet effective radius: Algorithm modification and preliminary application. J. Geophys. Res., 108, D24, 4763, doi:10.1029/2003JD003906, 2003.

Chen R., Wood, R., Li, Z., Ferraro, R., and Chang, F.-L.: Studying the vertical variation of cloud droplet effective radius using ship and space-borne remote sensing data, J. Geophys. Res., 113, D00A02, doi:10.1029/2007JD009596, 2008.

Hansen, J. E. and Travis, T. D.: Light scattering in planetary atmosphere, Space Sci. Rev., 16, 527-610, 1974.

Kato, S., Hinkelman, L. M., and Cheng, A.: Estimate of satellitederived cloud optical thickness and effective radius errors and their effect on computed domain-averaged irradiances, J. Geophys. Res., 111, D17201, doi:10.1029/2005JD006668, 2006.

King, M.: Determination of the Scaled Optical Thickness of Clouds from Reflected Solar Radiation Measurements. J. Atmos. Sci, 44.13, 1734-1751, 1987.

Lebsock, M. D., Stephens, G. L., and Kummerow, C.: Multisensor satellite observations of aerosol effects on warm clouds, J. Geophys. Res., 113, D15205, doi:10.1029/2008JD009876, 2008.

Leon, D. C., Wang, Z., and Liu, D., Climatology of drizzle in marine boundary layer clouds based on 1 year of data from CloudSat and CALIPSO, J. Geophys. Res., 113, DOOA14, doi:10.1029/2008JD009835, 2008.

Loeb, N. G., Varnai, T., and Winker, D. M.: Influence of subpixelscale cloud-top structure of reflectances from overcast stratiform cloud layers, J. Atmos. Sci., 55, 2960-2973, 1998.

Marshak, A., Platnick, S. E., Varnai, T., Wen, G., and Cahalan, R. F.: Impact of 3-D radiative effects on satellite retrievals of cloud droplet sizes, J. Geophys. Res., 111, DO9207, doi:10.1029/2005JD006686, 2006.

Mayer, B.: Radiative transfer in the cloudy atmosphere, Eur. Phys. J. Conferences, 1, 75-99, 2009.

Mayer, B., and Kylling, A.: Technical note: The libRadtran software package for radiative transfer calculations: description and examples of use, Atmos. Chem. Phys., 5, 1855-1877, doi:10.5194/acp-5-1855-2005, 2005.

Menzel, W. P., Frey, R., Zhang, H., Wylie, D., Moeller, C., Holz, R., Maddux, B., Baum, B. A., Strabala, K., and Gumley, L.: MODIS global cloud-top pressure and amount estimation: algorithm description and results, J. Appl. Meteor. Clim., 47, 11751198, 2008.

Minnis, P., Kratz, D. P., Coakley, J. A. Jr., King, M. D., Garber, D., Heck, P., Mayor, S., Young, D. F., and Arduini, R.: Cloud Optical Property Retrieval (Subsystem 4.3). "Clouds and the Earth's Radiant Energy System (CERES) Algorithm Theoretical Basis Document, Volume III: Cloud Analyses and Radiance Inversions (Subsystem 4)", edited by: CERES Science Team, NASA RP
1376 Vol. 3, 135-176, 1995.

Minnis, P., Arduini, R. F., Young, D. F., Ayers, J. K., Albracht, B. A., Sharon, T., Stevens, B.: An examination of the impact of drizzle drops on satellite retrieved effective particle sizes. Proceedings of the 14th International Conference on Clouds and Precipitation, Bologna, Italy, July 2004.

Nakajima, T. and King, K. D.: Determination of the Optical Thickness and Effective Particle Radius of Clouds from Reflected Solar Radiation Measurements. Part 1: Theory, J. Atmos. Sci., 47, 1878-1893, 1990.

Platnick, S.: Vertical photon transport in cloud remote sensing problems. J. Geophys. Res., 105(D18), 22919-22935, doi:10.1029/2000JD900333, 2000.

Platnick, S., Li, J. Y., King, M. D., Gerber, H., and Hobbs, P. V: A solar reflectance method for retrieving the optical thickness and droplet size of liquid water clouds over snow and ice surfaces, J. Geophys. Res., 106(D14), 15185-15199, 2001.

Platnick, S., King, M. D., Ackerman, S. A., Menzel, W. P., Baum, B. A., Riedi, J. C., and Frey, R. A.: The MODIS cloud products: Algorithms and examples from Terra, IEEE Trans. Geosci. Remote Sens., 41(2), 459-473, 2003.

Roebeling, R., Feijt, A., and Stammes, P.: Cloud property retrievals for climate monitoring: Implications of differences between Spinning Enhanced Visible and Infrared Imager (SEVIRI) on METEOSAT-8 and Advanced Very High Resolution Radiometer (AVHRR) on NOAA-17, J. Geophys. Res., 111, doi:10.1029/2005JD006 990, 2006.

Stevens, B., Vali, G., Comstock, K., Wood, R., van Zanten, M. C., Austin, P. H., Bretherton, C. S., and Lenschow, d. H.: Pockets of open cells and drizzle in marine stratocumulus, Bull. Am. Meteor. Soc., 51-57, 2005.

Vant-Hull, B., Marshak, A., Remer, L., and Li, Z.: The effects of scattering angle and cumulus cloud geometry on satellite retrievals of cloud drop effective radius, Geosci. Remote S., 45(4), 1039-1045, 2007.

Varnai, T. and Marshak A.: Statistical analysis of the uncertainties in cloud optical depth retrievals caused by three-dimensional radiative effects, J. Atmos. Sci., 58, 1540-1548, 2001.

Varnai, T. and Marshak, A.: View angle dependence of cloud optical thickness retrieved by MODIS. J. Geophys. Res., 112, D06203, doi:10.1029/2005JD006912, 2007.

Wood, R., Comstock, K. K., Bretherton, C. S., Cornish, C., Tomlinson, J., Collins, D. R., and Fairall, C.: Open cellular structure in marine stratocumulus sheets, J. Geophys. Res., 113, D12207, doi:10.1029/2007JD009371, 2008.

vanZanten, M. C., Stevens, B. B., Nuijens, L., Siebesma, A. P., Ackerman, A., Burnet, F., Cheng, A., Couvreux, F., Jiang, H., Khairoutdinov, M., Kogan, Y., Lewellen, D. C., Mechem, D., Nakamura, K., Noda, A., Shipway, B. J., Slawinska, J., Wang, S., and Wyszogrodzki, A.: Controls on precipitation and cloudiness in simulations of trade-wind cumulus as observed during RICO, submitted, J. Adv. Model. Earth Syst., 2010.

Zinner, T. and Mayer, B.: Remote sensing of stratocumulus clouds: Uncertainties and biases due to inhomogeneity, J. Geophys. Res., 111, D14209, doi:10.1029/2005JD006955, 2006. 